\title{
A EXISTÊNCIA COMO COMPREENSÃO DE SER
}

\author{
Crislane Barreto Santana-, Tatiane Boechat A. Zunino ${ }^{2}$ \\ 1. Bolsista PIBIC/FAPESB, Graduando em Filosofia, Universidade Estadual de Feira de Santana, e-mail: \\ crislanebarretto@gmail.com \\ 2. Orientadora, Departamento de Ciências Humanas e Filosofia, Universidade Estadual de Feira de Santana, e-mail: \\ tatiboechat@uefs.br
}

PALAVRAS-CHAVE: Significação; Compreensão de ser; Existência.

\section{INTRODUÇÃO}

A investigação apresentada no presente resumo consiste na análise da existência como compreensão de ser, conceitos expostos no tema investigativo, tal como "existência", "compreensão" e "ser", estão presentes na obra Ser e Tempo (1927) do filósofo alemão Martin Heidegger, que sustenta a base de todo pensar do vigente projeto. Introduzimos tal pensamento sob a ótica da condição do homem como um ente que não deve ser pensado separadamente do mundo que habita. Diante disso, a investigação filosófica sobre o conceito de homem, o qual será referido a partir de agora como Dasein, o ente que questiona seu próprio ser, que compreende as "coisas" a sua volta. "Dasein é uma palavra composta pelo verbo 'ser' (sein) e pelo advérbio 'aí' $(d a)$. Em acepção existencial-ontológica, o Dasein é ente cuja essência pertence ao ser; que existe enquanto (aí) - no aberto, em abertura para o Ser." (GIACOIA, 2013). Dito isto, investigamos como se dá a relação do Dasein com o sentido, partindo da primazia ontológica do Dasein como existência, que sustenta-se na fundamental pergunta sobre o sentido do ser, em correlação estreita à noção de ontologia fundamental que se deu como o fio condutor para está investigação. O Dasein é o único ente que compreende seu ser, e essa compreensão se dá através do modo de relacionar-se e comportar-se com os outros entes e consigo mesmo. Neste modo de comporta-se se dá a précompreensão, que deve ser entendida a priori na relação entre Dasein, mundo e linguagem, já que este ente tem como condição existencial ser-no-mundo e, por isso, abre campos de possibilidades.

\footnotetext{
Tomamos aqui como existenciais, todo modo originário de ser que se constitui como abertura existencial do Dasein; esses existenciais estruturam-se e se originam conjuntamente facultando o sentido e possibilitando ao Dasein formas de ação entrelaçadas ao mundo. Estas estruturas são chamadas de "existenciais" porque se referem às estruturas fundamentais do ente que "existe", o Dasein. Os existenciais são características fundamentais ontológicas do Dasein, que se determinam a partir de sua existência. Heidegger, 2014, § 4 e 9 pág.48/85.
}

Essas possibilidades nos aparecem no campo do compreensível e possível da interpretação, pois esta estrutura interpretativa torna possível o sentido uma vez que o perguntar constitui essencialmente o homem, ou seja, a linguagem possui o seu modo de ser no Dasein. Em Ser e Tempo, Heidegger propõem uma ontologia fundamental como tentativa de desconstrução da ontologia tradicional, tendo como ponto de partida uma fenomenologia hermenêutica. Para elucidar a questão fundamental de seu pensamento, a pergunta pelo sentido do ser, o filósofo retoma a tradição filosófica grega, a qual em sua história mostrou principal interesse na questão do ser. Para Heidegger, alguns filósofos deste período categorizaram o ser, caindo num equívoco carregado por grande parte da tradição fillosófica ocidental. A pergunta pelo sentido do ser não foi propriamente formulada,nem questionada em sua amplitude deste então. 


\section{MATERIAL E MÉTODOS OU METODOLOGIA (ou equivalente)}

Foram utilizados livros, artigos, resenhas, teses, dissertações, dicionários e vídeo-aulas como ferramentas complementares da pesquisa filosófica. A metodologia adotada é a da pesquisa bibliográfica aliada à análise textual, cuja finalidade se constitui numa consulta sistemática e cuidadosa de escritos correlatos ao tema e respectivo objetivo do presente resumo. $\mathrm{O}$ desenvolvimento da pesquisa tem como passo investigativo fundamental a leitura e análise de textos e conferências de autoria do filósofo Martin Heidegger, assim como comentários de estudiosos ligados à questão proposta. Consultamos também recursos digitais da literatura secundária que se mostraram pertinentes.

\section{RESULTADOS E/OU DISCUSSÃO (ou Análise e discussão dos resultados)}

Crítica à ontologia tradicional. Heidegger no primeiro capítulo de Ser e Tempo fala da "necessidade de uma retomada explícita da questão do ser". Segundo ele, esta questão foi lançada ao esquecimento, apesar de ter impulsionado as investigações de filósofos gregos, Heidegger jamais desmereceu a filosofia grega, no entanto, o pensamento grego por sua vez, na tentativa de interpretar o ser, acabou por estabelecer dogmas que tornaram redundante a temática apresentada. No intento em resgatar a questão ontológica que move a sua filosofia, Heidegger busca os prolegômenos que originaram o esquecimento do ser e aponta que desde Platão e Aristóteles a ideia de ser é marcada pela unificação entre ente e ser. Esse apontamento se dá pelo processo de descrição do que seja o ente, pois pela simples estrutura da pergunta "O que é o ser?" - já estamos "coisificando" ser, exigindo dele as mesmas perspectivas de respostas próprias ao ente. Assim, é preciso nos livrarmos de toda e qualquer predicação e atributos postos ao ser, como se ele fosse um ente qualquer. O filósofo chama de preconceitos os atributos ao ser que se fundam na ontologia tradicional, com isso pretende nos conduzir à discussão sobre a necessidade da recolocação sobre a questão do sentido do ser.

A diferença ontológica. De acordo com o pensamento heideggeriano, a temática da diferença ontológica é a sustentação de tudo aquilo ao qual movimenta a princípio o pensamento de Heidegger - ser e ente - possibilitando explicações acerca do sentido do ser e sobre o ser dos entes. A diferença ontológica representa de certo modo, uma pré-relação constitutiva entre ser e ente e ao modo de acontecer destes. Paralelamente, apresenta a presente diferença existente entre eles, tornando-a explícita sob diferentes modos de acontecer. Os conceitos "ôntico" e "ontológico" nos aproximam da diferença ontológica apresentada por Heidegger pela primeira vez em seu texto Da essência do fundamento em 1929, no qual nos mostra que o ente não é o ser, mas o ser é sempre ser de um ente, manifesto em tudo o que está aí, isto é, o ser está em tudo o que há, ou seja, em tudo o que nos aparece com sentido. A diferença ontológica é um conceito que mobiliza a filosofia heideggeriana a fim de resgatar a pergunta fundamental (pelo sentido e verdade do ser) esquecida pela tradição filosófica, empenhando-se na necessidade de apresentar a diferença existente entre ente e ser e que jamais devem ser concebidos como uma única "coisa".

Análise da estrutura formal da questão do sentido do ser. O filósofo esclarece a necessidade do questionar e analisar a estrutura da questão fundamental, com isso a indispensabilidade de investigar a questão do ser e seus momentos estruturais. Compreende-se então, que o Dasein, ente que questiona seu ser, é o primeiro a realizar esta ação e, do mesmo modo, passando a ser o questionado, direcionando-se ao sentido do ser. Heidegger nos conduz, assim, a compreender que sempre nos mantemos numa compreensão de ser, daí que eclode a questão explícita sobre o seu sentido.

A analítica existencial do Dasein. É preciso estruturar a analítica existencial do Dasein, a qual assume a especificidade introdutória à questão do sentido do ser. Heidegger 
afirma: "Uma analítica do Dasein, constitui, portanto, o primeiro desafio no questionamento da questão do ser." (HEIDEGGER, 2014). A analítica existencial do Dasein acontece a partir da constituição fundamental do próprio Dasein que é o ser-no-mundo. A expressão ser-nomundo nos indica um "fenômeno de unidade".

Dasein e mundo. Heidegger inicia sua investigação com uma questão fundamental, pensar o sentido do ser, ele compreende o Dasein como este ente privilegiado, que está lançado existencialmente ao mundo e o chama ser-no-mundo (In-der-Welt-sein). O modo de ser-no-mundo implica diretamente numa determinada concepção de mundo que ele chama de mundanidade do mundo. Para Heidegger, "a mundanidade é um conceito ontológico e significa a estrutura de um momento constitutivo de ser-no-mundo" (HEIDEGGER, 2014). Heidegger dirá que o "mundo" não deve ser tratado como um ente, não deve ser representado como um conjunto de coisas, tampouco como uma extensão sobre a qual se encontram as coisas, Dasein somente pode ser pensado, originariamente, se o considerarmos em seu caráter ontológico e existencial de "ser em um mundo". A noção de ser-no-mundo está vinculada a um dos existenciais que compõem a abertura do ser que é a compreensão, ela constitui a abertura originária para o sentido. O ser-no-mundo é condição fundamental para o existir do Dasein, sempre num processo constitutivo a partir da relação ser e mundo, e esse ser que se relaciona com o mundo é o ser aberto a possibilidades, aberto ao campo de sentido. Heidegger afirma que essa abertura é a compreensão própria do Dasein. Na analítica existencial, compreensão é vista como um modo fundamental desse ente que existe.

\section{CONSIDERAÇÕES FINAIS (ou Conclusão)}

A existência como compreensão do ser se dá no mundo. O ser-no-mundo é característica fundamental do existir do Dasein, visto que a compreensão é elemento fundamental na relação do Dasein com outros entes, pois ele é o único ente que compreende a si mesmo e aos outros entes e esta compreensão é possibilidade enquanto um ente de abertura para o sentido. O compreender não é algo dado, e sim, existencial, próprio do ser, toda compreensão é compreensão do modo de ser do Dasein enquanto aquele que compreende ser. Concluímos, dizendo que o pensamento de Heidegger parte sempre do pressuposto do homem no mundo como uma relação ontológica, o homem nunca deve ser pensado separadamente do mesmo, pois esta relação é o que define originariamente o seu existir. Heidegger nos leva a questionar tal relação, por isto, retoma a questão sobre o sentido do ser. Sendo assim, a compreensão é originária e constituinte da abertura do Dasein, sendo realizável a partir da lida ocupada, portanto, torna-se possível acessar os entes e compreendêlos enquanto sentido.

\section{REFERÊNCIAS}

HEIDEGGER, M. Ser e Tempo -Trad. Márcia de Sá Cavalcante. RJ: Vozes, 2014.

HEIDEGGER, M. O que é Metafísica? São Paulo: Nova Cultural, 1991 - (Coleção Os Pensadores).

HEIDEGGER, M. A Caminho da Linguagem. Petrópolis, RJ: Vozes, 2012.

HEIDEGGER, M.. Ensaios e Conferências. Petrópolis: Vozes, 2006.

BLANC, M. F. O fundamento em Heidegger. Lisboa: Piaget, 1984.

CASANOVA, M.A. Compreender Heidegger. Rio de Janeiro: Vozes, 2011.

DUBOIS, C. Heidegger: introdução a uma leitura. Rio de Janeiro: Jorge Zahar Ed., 2004.

GIACOIA, O. Heidegger urgente: introdução a um novo pensar. São Paulo: Três Estrelas. 2013. 